\title{
Genetic Diversity and Population Structure of North China Mountain Walnut Revealed by ISSR
}

\author{
Aiqing Ji1,2, Yina Wang1, Guoliang $\mathrm{Wu}^{1^{*}}$, Wenjiang $\mathrm{Wu}^{3}$, Hongyan Yang ${ }^{4}$, Qihai Wang1 \\ ${ }^{1}$ College of Horticultural Science, Henan Agricultural University, Zhengzhou, China \\ ${ }^{2}$ Department of Biology Science Technology, Jinzhong College, Jinzhong, China \\ ${ }^{3}$ Department of Food Science and Technology, Henan Agricultural University, Zhengzhou, China \\ ${ }^{4}$ Jinzhong Meteorological Bureau, Jinzhong, China \\ Email: *walnut-wu@126.com
}

Received 18 August 2014; revised 21 September 2014; accepted 17 October 2014

Copyright (C) 2014 by authors and Scientific Research Publishing Inc.

This work is licensed under the Creative Commons Attribution International License (CC BY).

http://creativecommons.org/licenses/by/4.0/

(c) (†) Open Access

\begin{abstract}
North China Mountain Walnut (NCMW) is one of the ancestors of extant cultivated species, and a valuable gene resource for resistance breeding of walnut in China. Inter-Simple Sequence Repeat (ISSR) primers were designed to evaluate the level and pattern of genetic diversity in eight populations of NCMW. Nine ISSR primers yielded 91 amplification products with different sizes, of which $84(92.31 \%)$ were polymorphic. A high species-level genetic diversity was detected with Nei's $(H=0.2592)$ and Shannon's diversity $(I=0.4003)$. In contrast, the population-level genetic diversity was relatively lower $(P P B=43.27 \%, H=0.1347, I=0.1862)$. Coefficient of populations differentiation $\left(G_{S T}\right)$ was 0.5066 , indicating that inter-population and intra-population variation contributed $50.66 \%$ and $49.34 \%$ respectively to the total genetic variability. This relative level of variation was further supported by AMOVA analysis. Limited gene flow $(\mathrm{Nm}=0.5133$.), habitat fragmentation and geographical isolation might be responsible for the population structure of NCMW. UPGMA cluster analysis classified the eight populations into three groups which showed no significant relationship between the genetic similarity coefficient and geographic origin but showed remarkable association with morpho-physiological characters, particularly nut traits. The results of the study provide species-level and population-level genetic profiles for further exploitation and conservation of genetic diversity of NCMW.
\end{abstract}

\section{Keywords}

North China Mountains Walnut (NCMW), Genetic Diversity, Population Structure, ISSR

\footnotetext{
${ }^{*}$ Corresponding author.
} 


\section{Introduction}

Several walnut (Juglans spp.) species are important dual purpose fruit and timber economic forest tree species, of these the globally most important is "Common Walnut" (J. regia). China is the one of origin centre of walnuts and possesses abundant resources. There are five main species of the Juglans genus available as walnut breeding resources in China. These are J. regia L., J. Sigillata Dode, J. mandshuria Maxim, J. openensis Hu, and J. nigra L. [1]. Due to walnut being seed propagated with open-pollination, walnut is highly variable with a diverse gene pool [2]. Walnuts in China have been divided into four ecotypes (Sinkiang Walnut, North China Mountain Walnut, Qinling-Daba Mountain Walnut and the Tibetan Highlands Walnut) in terms of their geographical distribution [3]. Genetic diversity research on North China Mountain Walnuts has developed slowly in comparison with the other three ecotypes in China.

In China, North China Mountain Walnuts are mainly distributed in the foothills of the North China Mountains, which spread across the northern latitudes from $35^{\circ}$ to $40^{\circ}$, and the western longitudes from $112^{\circ}$ to $119^{\circ}$. The area is a rocky, mountainous region with serious soil erosion, a warm temperate climate, an annual precipitation from $400-700 \mathrm{~mm}$, and slightly calcareous cinnamon soils [1]. Owing to the unique geography and climate, the endemic walnut varieties contain many agronomically excellent properties and specific valuable genes, such as for high content of protein, and strong disease and drought resistances [3], which have significant potential value for walnut variety improvement. In addition, the North China Mountains could be where J. regia L. and J. mandshurica Maxim were first domesticated and the region is one of the cultivated species' provenance [3]. Thus, the North China Mountain Walnut could possess a vast gene resource. However, in the past decade, under long-term biological or environmental pressure, the native walnut resources have been seriously damaged, which may result in increased homogeneity or reduction of genetic variability. The lack of systematic studies of genetic diversity among Chinese Juglans species and ecotypes could seriously restrict genetic improvement by limiting exploitation in walnut culture and breeding of many excellent traits found in these landrace lines. Accordingly, it is essential to properly characterize and assess the genetic diversity of landrace walnut resources for protection and breeding utilization.

In the past few years, a quantity of molecular markers, such as RFLP (Restriction Fragment-Length Polymorphism) [4] [5], RAPD (Randomly Amplified Polymorphic DNA) [6]-[9], AFLP (Amplified Fragment Length Polymorphism) [10] [11], SSR (Simple Sequence Repeat or microsatellites) [9] [12]-[17], and ISSR (Intersimple Sequence Repeat) [18] have been generally employed to examine genetic diversity and structure in walnut. While previous reports concentrated on the fingerprinting and genetic variability of walnut germplasm, there are few studies on the population genetic diversity of different ecotypes [16] [19] [20], especially the North China Mountain Walnut. ISSRs have been widely employed to evaluate genetic diversity of populations of economic forest tree species [21]-[23].

It is reported for the first time to assess genetic diversity and genetic structure of North China Mountain Walnut sampled out of eight significant natural populations in China by ISSR. We evaluate the population-level and species-level genetic diversity of eight North China Mountain Walnut populations throughout their known distribution by ISSR analysis to give some references for conservation measures and germplasm resource development and utilization.

\section{Materials and Methods}

\subsection{Plant Material and Sampling Strategy}

In this study, a total of 138 individuals of North China Mountain Walnut, representing eight populations (GX, FY, LY, YX, LC, SX, ZQ, and LZ), were sampled across three provinces in China, including Shanxi, Hebei and Henan along the Taihang and Lvliang Mountains (Figure 1 and Table 1). The collection locations represented a wide geographic distribution of North China Mountain Walnut. Interpopulation distance ranged from a minimum of $30.8 \mathrm{~km}$ (LC-SX) to a maximum of $512 \mathrm{~km}$ (LZ-LY). The number of samples analyzed depended on the usability of adult plants ( $>80 \mathrm{~cm}$ at breast height diameter) in each sampling location. In each population, 4 - 25 adult walnut trees were randomly sampled at the distance exceeding at least $50 \mathrm{~m}$ from each other to reduce the probability of sampling from family clusters. From each individual tree, fresh mature leaves were randomly sampled, stored in plastic bags and taken to the lab for experimental studies. 


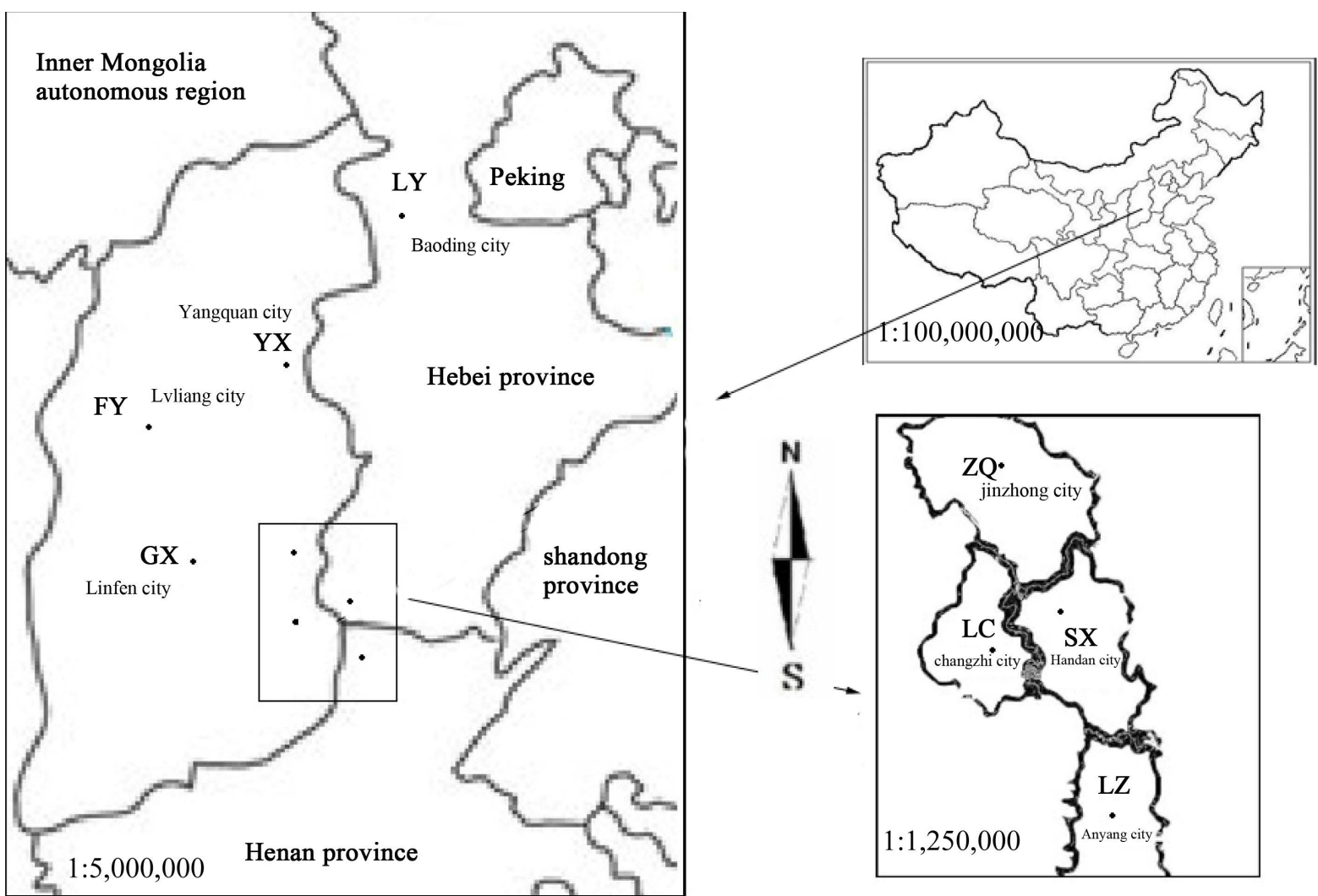

Figure 1. Geographic locations of sampling sites for the eight natural populations of North China Mountain Walnut examined in this study. The abbreviations of GX, FY, LY, YX, LC, SX, ZQ and LZ follow those used in Table 1.

Table 1. Location and sampling size of eight nature populations of North China Mountains walnut.

\begin{tabular}{ccccc}
\hline Population & Location & Longitude (E)/Latitude (N) & Elevation (m) & Sample sizes \\
\hline GX & Gu County, Linfen City, Shanxi Province & $36^{\circ} 32^{\prime} \mathrm{N} 112^{\circ} 04^{\prime} \mathrm{E}$ & 1430 & 15 \\
FY & Fengyang County, Luliang City, Shanxi Province & $37^{\circ} 15^{\prime} \mathrm{N} 111^{\circ} 37^{\prime} \mathrm{E}$ & 1047 & 15 \\
ZQ & Zunquan County, Jinzhong City, Shanxi Province & $36^{\circ} 51^{\prime} \mathrm{N} 113^{\circ} 27^{\prime} \mathrm{E}$ & 821 & 23 \\
YX & Yu County, Yangquan City, Shanxi Province & $38^{\circ} 23^{\prime} \mathrm{N} 113^{\circ} 21^{\prime} \mathrm{E}$ & 653 & 20 \\
LC & Licheng County, Changzhi City, Shanxi Province & $36^{\circ} 48^{\prime} \mathrm{N} 113^{\circ} 27^{\prime} \mathrm{E}$ & 757 & 25 \\
SX & Shexian County, Handan City, Hebei Province & $36^{\circ} 411^{\prime} \mathrm{N} 113^{\circ} 27^{\prime} \mathrm{E}$ & 562 & 11 \\
LY & Laiyuan County, Baoding City, Hebei Province & $39^{\circ} 53^{\prime} \mathrm{N} 118^{\circ} 53^{\prime} \mathrm{E}$ & 45 & 8 \\
HN & Linzhou County, Anyang City, Henna Province & $36^{\circ} 16^{\prime} \mathrm{N} 113^{\circ} 48^{\prime} \mathrm{E}$ & 420 & 4 \\
\hline
\end{tabular}

\subsection{DNA Extraction}

Genomic DNA was extracted from storage leaves of walnut by using the optimized Cetyl Trimethyl Ammonium Bromide (CTAB) method [11]. Total DNA quality was checked by gel electrophoresis and DNA concentration was determined by Biophotometer protein nucleotide analyzer (Eppendorf, Germany). Purified DNA was diluted to approximately $30 \mathrm{ng} \cdot \mu \mathrm{L}^{-1}$ prior to polymerase chain reaction (PCR) amplification, and preserved in the refrigerator at $-20^{\circ} \mathrm{C}$.

\subsection{ISSR-PCR Amplification}

A total of one hundred ISSR primers were used. The primers were designed according to public sequences pro- 
vided by the University of British Columbia, Canada and biosynthesised by the Shanghai Sangon Biological Engineering Technology \& Services Co. Ltd. (Shanghai, China). They were sifted firstly grounded on one sample from each population. Nine primers, which yielded clear, polymorphic, and reproducible bands, were used for the further genetic diversity analysis of all 138 DNA individuals (Table 2). PCR reactions were performed in $25 \mu \mathrm{l}$ reaction mixture containing $2.5 \mu \mathrm{l}$ of $10 \times$ buffer, $1 \mathrm{U}$ Taq polymerase, $0.2 \mu \mathrm{M}$ dNTP (Tiangen Biotech (Beijing) Co., Ltd), $0.2 \mu \mathrm{M}$ primer and $30 \mathrm{ng}$ of genomic DNA. Amplification was carried out in a thermocycler (Peltier Thermal Cycler PTC-200, MJ research, USA) as follows: initial denaturation of $5 \mathrm{~min}$ at $94^{\circ} \mathrm{C}$, followed by 35 cycles of denaturation of $30 \mathrm{~s}$ at $94^{\circ} \mathrm{C}$, annealing of $45 \mathrm{~s}$ at $51^{\circ} \mathrm{C}-60^{\circ} \mathrm{C}$ (based on the used primer), and extension of $1.5 \mathrm{~m}$ at $72^{\circ} \mathrm{C}$, followed by a final extension of $7 \mathrm{~m}$ at $72^{\circ} \mathrm{C}$. The amplification products were separated on $2.0 \%$ agarose gels in $0.5 \times$ TBE buffer at a constant voltage of $80 \mathrm{~V}$, for $2 \mathrm{~h}$ along with $100 \mathrm{bp}$ DNA ladder marker (100 - $1500 \mathrm{bp)}$ ) and stained by $0.1 \%$ ethidium bromide. The gel images were then visualized and recorded using a Bio-Rad Gel Doc $2000^{\mathrm{TM}}$ system (USA).

\subsection{Data Analysis}

Polymorphic bands were scored visually as either present " 1 " or absent " 0 " to form a binary matrix. On the supposition of Hardy-Weinberg equilibrium, POPGENE versions 1.31 [24] were employed to compute the following basic statistics. To assess genetic diversity at species level and population level, the parameters calculated included; percentages of polymorphic bands (PPB\%), mean number of alleles $(\mathrm{Na})$, mean effective number of alleles $(\mathrm{Ne})$, Nei's gene diversity index $(H)$ and Shannon-diversity index $(I)$. To evaluate gene differentiation between populations, the parameters calculated included Nei's coefficient of population differentiation $\left(G_{S T}\right)$ with the formula: $G_{\mathrm{ST}}=(\mathrm{Ht}-\mathrm{Hs}) / \mathrm{Ht}$ [25], and Gene flow among populations $(\mathrm{Nm})$ which was calculated using the formula of $N m=\left(1-G_{S T}\right) / 2 G_{S T}$. Genetic relationships among populations were estimated by Nei's unbiased genetic distances $(D)$ and genetic identities $(I)$ using NTSYSpc-2.0 [26], and a cluster analysis was performed using UPGMA (the Unweighted Pair Group Method with Arithmetic mean) [27]. In addition, population differentiation coefficients within and among the populations were computed from AMOVA 1.55 (analysis of molecular variance) [28].

\section{Results}

\subsection{Genetic Diversity}

91 bands in total were generated from nine screened primers for the 138 individual samples from the eight populations, of which 84 (92.13\%) were polymorphic bands. The size of the amplified band ranged from 300 bp to $1200 \mathrm{bp}$. The percentage of polymorphic band (PPB) of the 9 ISSR primers differed from $66.67 \%$ (UBC855) to 100\% (UBC815, UBC836, UBC840 and UBC853), with an average of 92.31\%. The number of bands presented by each primer also differed from 6 (UBC855) to 11 (UBC840) with an average of 10.11 (Table 2).

Estimates of genetic diversity in eight populations of North China Mountain Walnut are summarized in Table 3.

Table 2. Polymorphic bands generated by ISSR in eight nature populations of NCMW.

\begin{tabular}{cccccc}
\hline Primer & Sequencea & Tmb/ ${ }^{\circ} \mathrm{C}$ & Number of band & Number of polymorphic band & PPB/\% \\
\hline UBC811 & (GA)8C & 54.7 & 11 & 9 & 81.82 \\
UBC815 & (CT)8A & 59.1 & 10 & 10 & 100 \\
UBC836 & $($ AG)8YA & 52.5 & 8 & 8 & 100 \\
UBC840 & (GA)8YT & 50.6 & 15 & 15 & 100 \\
UBC843 & (CT)8RC & 54.3 & 10 & 8 & 80 \\
UBC853 & (TC)8RT & 55.2 & 11 & 11 & 100 \\
UBC855 & (AC)8YT & 51.8 & 6 & 4 & 66.67 \\
UBC856 & (AC)8YA & 56.1 & 9 & 9 & 100 \\
UBC888 & BDB(CA)7 & 53.4 & 11 & 9.33 & 90.91 \\
\end{tabular}

$\mathrm{Y}=(\mathrm{C}, \mathrm{T}), \mathrm{R}=(\mathrm{A}, \mathrm{G}), \mathrm{B}=(\mathrm{C}, \mathrm{G}, \mathrm{T}), \mathrm{D}=(\mathrm{A}, \mathrm{G}, \mathrm{T}) .{ }^{\mathrm{a}}$ Sequence $5^{\prime}-3^{\prime}$; ${ }^{\mathrm{b}} \mathrm{PCR}$ reaction annealling temperature for tabulated primers $\left({ }^{\circ} \mathrm{C}\right)$; ${ }^{\mathrm{C}} \mathrm{Percentage}$ of polymorphic band. 
Table 3. Genetic diversity analysis of 8 populations of North China Mountain based on ISSR markers.

\begin{tabular}{ccccccc}
\hline Population & Number of polymorphic loci & $P P B(\%)$ & $N a$ & $N e$ & $H$ & $I$ \\
\hline GX & 48 & 52.75 & 1.575 & 1.3024 & 0.1788 & 0.2695 \\
YX & 30 & 32.97 & 1.3297 & 1.1505 & 0.0955 & 0.1496 \\
LY & 38 & 41.76 & 1.4176 & 1.1795 & 0.1098 & 0.1716 \\
FY & 52 & 57.14 & 1.5714 & 1.3163 & 0.1839 & 0.2778 \\
LC & 39 & 42.86 & 1.4286 & 1.1769 & 0.1090 & 0.1717 \\
SX & 41 & 45.05 & 1.4505 & 1.2764 & 0.1617 & 0.2413 \\
ZQ & 49 & 53.85 & 1.5385 & 1.2584 & 0.1569 & 0.2433 \\
HN & 18 & 19.78 & 1.1978 & 1.1419 & 0.0818 & 0.1192 \\
Average & 39.375 & 43.27 & 1.4386 & 1.2253 & 0.1347 & 0.1862 \\
Species & 84 & 92.31 & 1.9231 & 1.4243 & 0.2592 & 0.4003 \\
SD & & & 0.2679 & 0.3335 & 0.1699 & 0.2290 \\
\hline
\end{tabular}

$P P B$, Percentage of polymorphic loci (\%); Na, Observed number of alleles; $N$, Effective number of alleles; $H$, Nei's genetic diversity; $I$, Shannon’s information index; $S D$, Indicates the standard deviation.

At the species level, the effective number of alleles $(\mathrm{Ne})$, Nei's genetic diversity $(H)$ and the Shannon information index $(I)$ were 1.4243, 0.2592, 0.4003 respectively. At the population level, $P P B$ ranged from $19.78 \%$ for the LZ population to $57.14 \%$ for the YX population, with an average of $43.27 \%$, and the average $\mathrm{Ne}, \mathrm{H}$, and $\mathrm{I}$ were $1.2253,0.1347$, and 0.1862 , respectively. The results showed that the genetic diversity of North China Mountain Walnuts from the YX population $(N e=1.3163, H=0.1839, I=0.2778)$ was the richest in three estimates among the eight populations and the lowest diversity was exhibited in the LZ population.

\subsection{Genetic Differentiation}

Nei's coefficient of genetic differentiation $\left(G_{S T}\right)$ was 0.5066 , which showed that $50.66 \%$ of the total genetic variability is attributed to inter-populations and $49.34 \%$ intra-populations. Results of AMOVA also agreed with which genetic differentiation inter-populations is relatively high $\left(F_{S T}=0.5161\right)$. At two hierarchical levels, 51.61\% of the total genetic variation was partitioned inter-populations, and $48.39 \%(\mathrm{P}<0.001)$ intra-populations. The level of gene flow $(\mathrm{Nm})$ was estimated to be only 0.5133 , which implied that a low gene flow would not prevent genetic drift thus enabling the gene differentiation between populations.

\subsection{Genetic Similary and Genetic Distance among Populations}

To further clarify the gene differentiation among different populations, Nei's pairwise genetic similary coefficients were assessed. Genetic similar coefficients varied from 0.7423 to 0.9298 with an average 0.8159 , which showed higher levels of genetic differentiation partitioned among populations of North China Mountain Walnut. The highest similar coefficient was between the ZQ population and the LC population, while difference in similary coefficients between the FY population and the LC population was revealed as the lowest (Table 4).

In order to further illustrated relationships among populations, a dendrogram generated by UPGMA algorithm based on Nei's genetic similary, which clustered the eight populations into three major groups (Figure 2). The first group included five populations (ZQ, LC, SX, YX and LY), distributed along the main vein of Taihang Mountains, the second group comprised GX and FY populations, located in the south of Taiyue Mountains and east of Lvliang Mountains respectively, while LZ alone formed the third group, located in the east of Taihang Mountains. However, the cluster result was not necessarily relationship with geographic separation. Such as, the ZQ population had a much greater geographic separation from the LY population than the LZ population, but ZQ clustered together with the LY population and not with the LZ population in the dendrogram. Therefore, geographical distance alone cannot account for the genetic distance between populations.

\section{Discussion}

\subsection{Genetic Diversity}

Our data shows that genetic diversity is higher at the species level $(P P B=92.31 \%, H=0.2592, I=0.4003)$, but 
Table 4. Nei’s unbiased genetic identity (above diagonal) and genetic distance (below diagonal) among eight nature populations of North China walnut.

\begin{tabular}{|c|c|c|c|c|c|c|c|c|}
\hline Population & GX & FY & LY & YX & LC & SX & ZQ & HN \\
\hline GX & $* * * *$ & 0.8567 & 0.7954 & 0.7892 & 0.8077 & 0.8337 & 0.7913 & 0.8024 \\
\hline FY & 0.1546 & ${ }^{* * * *}$ & 0.7658 & 0.7451 & 0.7423 & 0.7562 & 0.7653 & 0.7562 \\
\hline LY & 0.2289 & 0.2668 & $* * * *$ & 0.8751 & 0.8891 & 0.8735 & 0.8740 & 0.8424 \\
\hline YX & 0.2367 & 0.2943 & 0.1334 & $* * * *$ & 0.9011 & 0.8868 & 0.8709 & 0.8350 \\
\hline LC & 0.2136 & 0.2979 & 0.1176 & 0.1041 & $* * * *$ & 0.9102 & 0.9298 & 0.8259 \\
\hline SX & 0.1818 & 0.2794 & 0.1353 & 0.1202 & 0.0941 & $* * * *$ & 0.8993 & 0.8454 \\
\hline ZQ & 0.2340 & 0.2675 & 0.1346 & 0.1382 & 0.0728 & 0.1062 & $* * * *$ & 0.8761 \\
\hline $\mathrm{HN}$ & 0.2201 & 0.2795 & 0.1715 & 0.1804 & 0.1913 & 0.1679 & 0.1322 & $* * * *$ \\
\hline
\end{tabular}

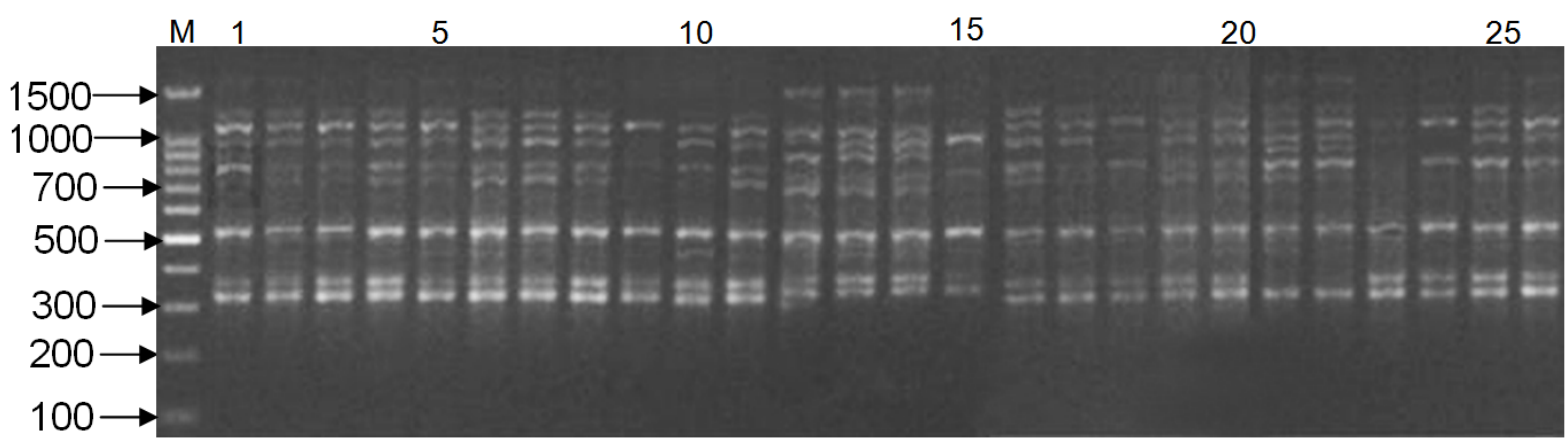

Figure 2. ISSR amplification results with primer UBC811 for GX population.

lower at population level $(P P B=43.27 \%, H=0.1347, I=0.1862)$, which is alike to the results obtained from same species using different molecular markers [17] [19] [20]. When compared with many other economic tree species using ISSR, North China Mountain Walnut maintains higher species diversity (e.g. gingko [29], Emmenopterys henryi [30], etc.). The higher species diversity may largely be attributed to walnut breeding systems. The walnut is wind pollinated. When compared with insect pollination, the smaller wind carried pollen is easier to spread. In addition, walnut has unisexual flowers and a monoecious plant, which may carry out both geitonogamy and cross pollination, but due to dichogamy, the same cultivars or strains while self fertile may not be able to pollinate itself, which results in frequent gene flow among individuals and increases the chance of gene recombination. Geographical distribution would be another key factor that determines genetic diversity level of a species. The North China Mountain Walnut is distributed mostly in rocky Mountainous areas, which have serious soil erosion and calcareous cinnamon soils. The need and hence ability to adapt to different environments results in a higher level of genetic diversity.

North China Mountain Walnuts are distributed in different ecological environments and geographic conditions, such as having a range of growing elevations from $45 \mathrm{~m}$ to $1430 \mathrm{~m}$ above sea level. With increasing elevation, climate and soil physicochemical properties also show a significant change, which results in greater population variation. As observed in our study, the population differentiation parameters such as $P P B, N e, H$ and $I$ in eight populations showed a similar pattern, the YX population is the highest, and the LZ population is the lowest. This can be interpreted as a consequence of habitat fragmentation and small numbers of individuals. Due to genetic drift, small populations tend to lose genetic variation has been verified in many studies. Therefore, the results need to be further studied and verified by a more extensive investigation.

Compared with other ecotypes, genetic diversity of North China Mountain Walnut was at a moderate level, which was marginally higher than Sinkiang walnut and Qinling-Daba Mountain walnut [31], but was lower than Tibet walnut [17]. The result of this study supported the conclusion that the Tibet walnut population diversity was generally higher than other ecotypes populations [17].

\subsection{Populations Genetic Structure}

In accordance with the $G_{S T}$ value $\left(G_{S T}=0.5066\right)$, found in this study a significant amount of genetic differentia- 
tion is observed among and within eight populations of North China Mountain Walnut. This point is reinforced by the AMOVA, which indicating that $51.61 \%$ of the genetic variation was partitioned inter-populations and 49.34\% intra-populations. Significant genetic differentiation was also reported by Wu et al. using RAPD. In contrast, less genetic differentiation was found by Xi [3] using a bioecological survey method and peroxidase isoenzymatics marker. The difference might be due to the sampling locations, sampling size, and the different marker systems used. Similar studies have shown that there are inconsistencies in genetic differentiation value found between populations when using different genetic markers in other species populations [32] [33].

High genetic differentiation of North China Mountain Walnut is attributed to the following points: Firstly, because of low gene flow of the North China Mountain Walnut habitat $(\mathrm{Nm}=0.5133)$, the present population structure was shaped by genetic drift mainly. Secondly, the Taihang and Lvliang Mountains contribute to the geographical isolation, which severely hindered dispersal of pollen or seeds and exchange of genes between populations, ultimately promoting the large genetic differentiation among populations. Thirdly, in order to adapt to the diverse habitats of the region in the evolutionary process, variants to some extent occurred, which may have been preserved and fixed gradually due to limited gene flow, thereby, genetic differentiation among populations occurred. The $G_{S T}$ value and AMOVA analysis results obtained in this study indicated that North China Mountain Walnut has a significant genetic differentiation among populations, which suggests that the species has a strong environmental adaptability. Put briefly, high genetic variation among populations is due to genetic drift and geographical isolation of the populations.

Based on the genetic similarity, eight populations of North China Mountain Walnut were grouped into three clusters, but genetic differentiation did not completely cluster according to geographical distances (Figure 3). This supported the conclusion that owing to the complex origin and affiliation of walnut, there isn't an obvious association between genetic similarity and geographic origin [11]. But the results of cluster analysis did correspond with phenetic classification systems of local varieties. Mian walnut, with a less developed endoseptum, a slightly colored and a slightly veiny shell, is the main variety in the LC, ZQ and SX populations; it is characterized by large fruit size, thin and smooth shell and pale yellow kernels in the LY and YX population; the Fenzhou and Guxian walnut is well known to have a thin shell, full kernels, higher kernel crackout, milky white kernels in the FY and GX population, respectively; the varieties of the LZ population are Mian walnut and Jia walnut with thicker, corrugated and tawny shell and low kernel crackout. Whether these differences are due to genetic drift still needs to be determined.

\subsection{Conservation Implications}

To know about the geographic structure of intraspecific genetic variation is indispensable for the protection of germplasm resources. Our study provides an insight into genetic diversity and genetic differentiation at population levels of North China Mountain Walnut, and indicates a decrease of genetic diversity caused by genetic drift is unacceptable. Accordingly, so as to secure existing diversity, preservation areas covering large popula-

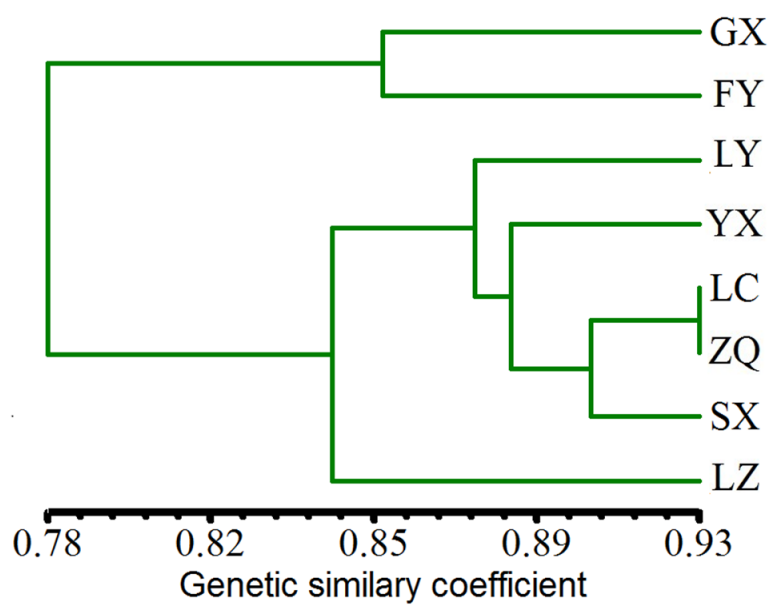

Figure 3. UPGMA dendrogram for 8 populations of North China Mountain Walnut based on genetic identity. 
tions as well as many small populations should be established. Mixing genetically diverse populations of North China Mountain Walnut in situ or ex situ is unacceptable in conservation.

\section{Acknowledgements}

We gratefully thank Professor Chuck Leslie at Department of Plant Sciences, University of California, Davis; and Jihua Tang at Henan Agriculture University, for critically reviewing our manuscript. This work was financially supported by the National Natural Science Foundation of China (31171943), the Key Scientific and Technological Project in Henan province (92101110600), and the Scientific and Technological Project in Henan province (102102110178).

\section{References}

[1] Wu, G.L., Liu, Q.L., Zheng, X.B., Song, Y.Q., Jian, Z.H. and Peng, G.B. (2009) Advances in Research on the Worldwide Walnut Germplasmm. Journal of Fruit Science, 26, 539-545. (In Chinese)

[2] Ebrahimi, A., Fatahi, R. and Zamani, Z. (2011) Analysis of Genetic Diversity among Some Persian walnut Genotypes (Juglans regia L.) Using Morphological Traits and SSRs Markers. Scientia Horticulturae, 130, 146-151. http://dx.doi.org/10.1016/j.scienta.2011.06.028

[3] Xi, S.K. (1987) Gene Resources of Juglans and Genetic Improvement of Juglans regia in China. Scientia Silvae Sinicae, 23, 342-349. (In Chinese)

[4] Fjellstrom, R.G., Parfitt, D.E. and McGranahan, G.H. (1994) Genetic Relationship and Characterization of Persian walnut (Juglans regia L.) Cultivars Using Restriction Fragment Length Polymorphisms (RFLPs). Journal of the American Society for Horticultural Science, 119, 833-839.

[5] Fjellstrom, R.G. and Parfitt, D.E. (1994) Walnut (Juglans spp.) Genetic Diversity Determined by Restriction Fragment Length Polymorphisms. Genome, 37, 690-700. http://dx.doi.org/10.1139/g94-097

[6] Nicese, F.P., Hormaza, J.I. and McGranahan, G.H. (1998) Molecular Characterization and Genetic Relatedness among Walnut (Juglans regia L.) Genotypes Based on ISSR Markers. Euphytica, 101, 199-206. http://dx.doi.org/10.1023/A:1018390120142

[7] Wu, Y.M., Pei, D., Xi, S.K. and Li, J.R. (2000) A Study on the Genetic Relationship among Species in Juglans L. Using RAPD Markers. Acta Horticulturae Sinica, 27, 17-22. (In Chinese)

[8] Wu, Y.M., Liu, Y., Dong, F.X. and Xi, S.K. (2000) Study on Different Ecological Types of Chinese Walnut (J. regia) Using RAPD Markers. Journal of Beijing Forestry Universitty, 22, 23-27. (In Chinese)

[9] Nazeer, A., Mir, J.I., Reyazul, R.Mir., Nazir, A.R., Rizwan, R., Shabir, H.W., Wajida, S., Hidayatullah, M. and Sheikh, M.A. (2012) SSR and RAPD Analysis of Genetic Diversity in Walnut (Juglans regia L.) Genotypes from Jammu and Kashmir, India. Physiology and Molecular Biology of Plants, 18, 149-160. http://dx.doi.org/10.1007/s12298-012-0104-z

[10] Bayazit, S., Kazan, K., Gulbitti, V., Evik, C., Ayanoglu, H. and Ergul, A. (2007) AFLP Analysis of Genetic Diversity in Low Chilling Requiring Walnut (Juglans regia L.) Genotypes from Hatay, Turkey. Scientia Horticulturae, 111, 394-398. http://dx.doi.org/10.1016/j.scienta.2006.11.006

[11] Wang, H.X., Zhao, S.G., Gao, Y., Zhang, Z.H. and Xuan, L.C. (2011) Genetic Diversity of Juglans regia L. Cultivars Revealed by AFLP Analysis. Scientia Agricultura Sinica, 44, 1434-1442. (In Chinese)

[12] Dangl, G.S., Woeste, K., Aradhya, M.K., Koehmstedt, A., Simon, C., Potter, D., Leslie, C.A. and McGranahan, G. (2005) Characterization of 14 Microsatellite Markers for Genetic Analysis and Cultivar Identification of Walnut. Journal of the American Society for Horticultural Science, 130, 348-354.

[13] Foroni, I., Rao, R., Woeste, K. and Gallitelli, M. (2005) Characterization of (Juglans regia L.) with SSR Markers and Evaluation of Genetic Relationships among Cultivars and the "Sorrento" Landrace. The Journal of Horticultural Science and Biotechnology, 80, 49-53.

[14] Victory, E.R., Jeffrey, C., Glaubitz, O.E., Rhodes, J.R. and Woeste, K.E. (2006) Genetic Homogeneity in Juglans nigra (Juglandaceae) at Nuclear Microsatellites. American Journal of Botany, 93, 118-126. http://dx.doi.org/10.3732/ajb.93.1.118

[15] Wang, H., Hao, J.M., Wang, B.Q. and Pei, D. (2007) SSR Analysis of Genetic Diversity of Eight Natural Walnut Populations in China. Scientia Silvae Sinicae, 43, 120-124. (In Chinese)

[16] Wang, H., Pei, D., Gu, R.S. and Wang, B.Q. (2008) Genetic Diversity and Structure of Walnut Populations in Central and Southwestern China Revealed by Microsatellite Markers. Journal of the American Society for Horticultural Science, 1332, 197-203. 
[17] Wang, H. (2010) Genetic Diversity of Germplasm Resources on Walnut in Tibet Region. Thesis, Chinese Academy of Forestry Sciences, Peking, 77-78. (In Chinese)

[18] Potter, D., Gao, F., Aiello, G., Leslie, C. and McGranahan, G. (2002) Intersimple Sequence Repeat Markers for Fingerprinting and Determining Genetic Relationships of Walnut (Juglans regia) Cultivars. Journal of the American Society for Horticultural Science, 127, 75-81.

[19] Christopoulosa, M.V., Dimos, R., Eleni, T. and Penelope, J.B. (2010) Germplasm Diversity and Genetic Relationships among Walnut (Juglans regia L.) Cultivars and Greek Local Selections Revealed by Inter-Simple Sequence Repeat (ISSR) Markers. Scientia Horticulturae, 125,584-592. http://dx.doi.org/10.1016/j.scienta.2010.05.006

[20] Li, C., Luo, S.P., Zeng, B., Li, J. and Li, G. (2011) Analysis of Genetic Diversity of Germplasm Resources of Walnut (Juglans regia L.) Revealed by ISSR in Xinjiang of China. Scientia Agricultura Sinica, 44, 1871-1879.

[21] Thimmappaiah, W.G., Santhosh, D., Shobha, G.S. and Melwyn, G.S. (2009) Assessment of Genetic Diversity in Cashew Germplasm Using RAPD and ISSR Markers. Scientia Horticulturae, 120, 411-417. http://dx.doi.org/10.1016/j.scienta.2008.11.022

[22] Ai, C.X., Zhang, L.S., Wei, H.R., Jin, S.N., Yuan, K.J. and Liu, Q.Z. (2007) Study on the Genetic Diversity of Natural Chestnut of Shandong by ISSR. Chinese Journal of Biotechnology, 23, 628-633. (In Chinese) http://dx.doi.org/10.1016/S1872-2075(07)60043-0

[23] Kamalesh, S.M., Tikam, S.R. and Shirish, A.R. (2011) Molecular Analyses of Genetic Variability in Soap Nut (Sapindus mukorossi Gaertn.). Industrial Crops and Products, 34, 1111-1118. http://dx.doi.org/10.1016/j.indcrop.2011.03.029

[24] Yeh, F.C., Yang, R.C. and Boyle, T. (1999) POPGENE Version 1.32: Microsoft Window-Based Freeware for Population Genetics Analysis. University of Alberta, Edmonton.

[25] Nei, M. (1973) Analysis of Gene Diversity in Subdivided Populations. Proceedings of the National Academy of Sciences of the United States of America, 70, 3321-3323. http://dx.doi.org/10.1073/pnas.70.12.3321

[26] Rohlf, F.J. (2000) NTSYS-Pc: Numerical Taxonomy and Multivariate Analysis System. Version 2.1., Exeter Publishing Led., New York.

[27] Nei, M. (1978) Estimation of Average Heterozygosity and Genetic Distance from a Small Number of Individuals. Genetics, 89, 583-590.

[28] Excoffier, L., Smouse, P. and Quattro, J.M. (1992) Analysis of Molecular Variance Inferred from Metric Distances among DNA Haplotypes: Application to Human Mitochondrial DNA Restriction Data. Genetics, 131, 479-491.

[29] Ge, Y.Q., Qiu, Y.X., Ding, B.Y. and Fu, C.X. (2003) An ISSR Analysis on Population Genetic Diversity of the Relict Plant Ginkgo biloba. Biodiversity Science, 11, 276-287. (In Chinese)

[30] Li, J.M. and Jin, Z.C. (2008) Genetic Structure of Endangered Emmenopterys henryi Oliv. Based on ISSR Polymorphism and Implications for Its Conservation. Genetica, 133, 227-234. http://dx.doi.org/10.1007/s10709-007-9204-Z

[31] Li, G.T., Ai, C.X., Zhang, L.S., Wei, H.R. and Liu, Q.Z. (2011) ISSR Analysis of Genetic Diversity among Seedling Walnut (Juglans spp.) Populations. Journal of Plant Genetic Resources, 12, 640-645. (In Chinese)

[32] Freville, H., Justy, F. and Olivieri, I. (2001) Comparative Allozyme and Microsatellite Population Structure in a Narrow Endemic Plant Species, Centaurea corymbosa Pourret (Asteraceae). Molecular Ecology, 10, 879-889. http://dx.doi.org/10.1046/j.1365-294X.2001.01249.x

[33] Maguire, T.L., Peakall, R. and Saenger, P. (2002) Comparative Analysis of Genetic Diversity in the Mangrove Species Avicennia marina (Forsk.) Vierh. (Avicenniaceae) Detected by AFLPs and SSRs. Theoretical and Applied Genetics, 104, 388-398. http://dx.doi.org/10.1007/s001220100724 
Scientific Research Publishing (SCIRP) is one of the largest Open Access journal publishers. It is currently publishing more than 200 open access, online, peer-reviewed journals covering a wide range of academic disciplines. SCIRP serves the worldwide academic communities and contributes to the progress and application of science with its publication.

Other selected journals from SCIRP are listed as below. Submit your manuscript to us via either submit@scirp.org or Online Submission Portal.
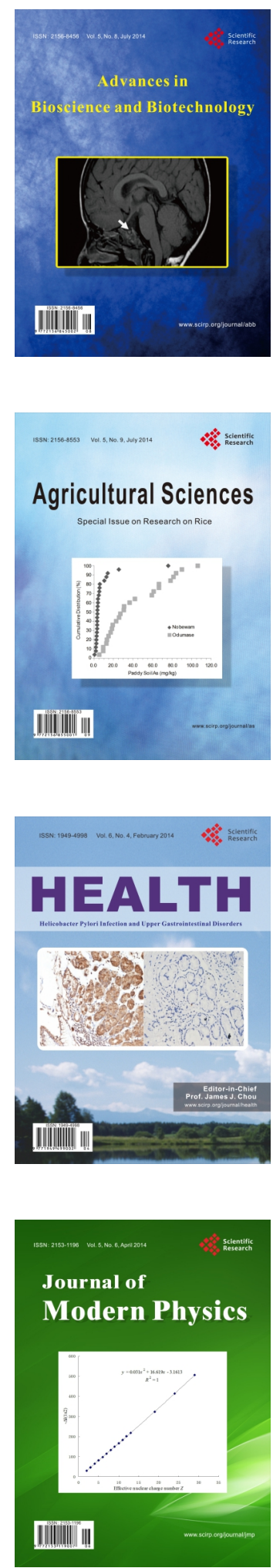
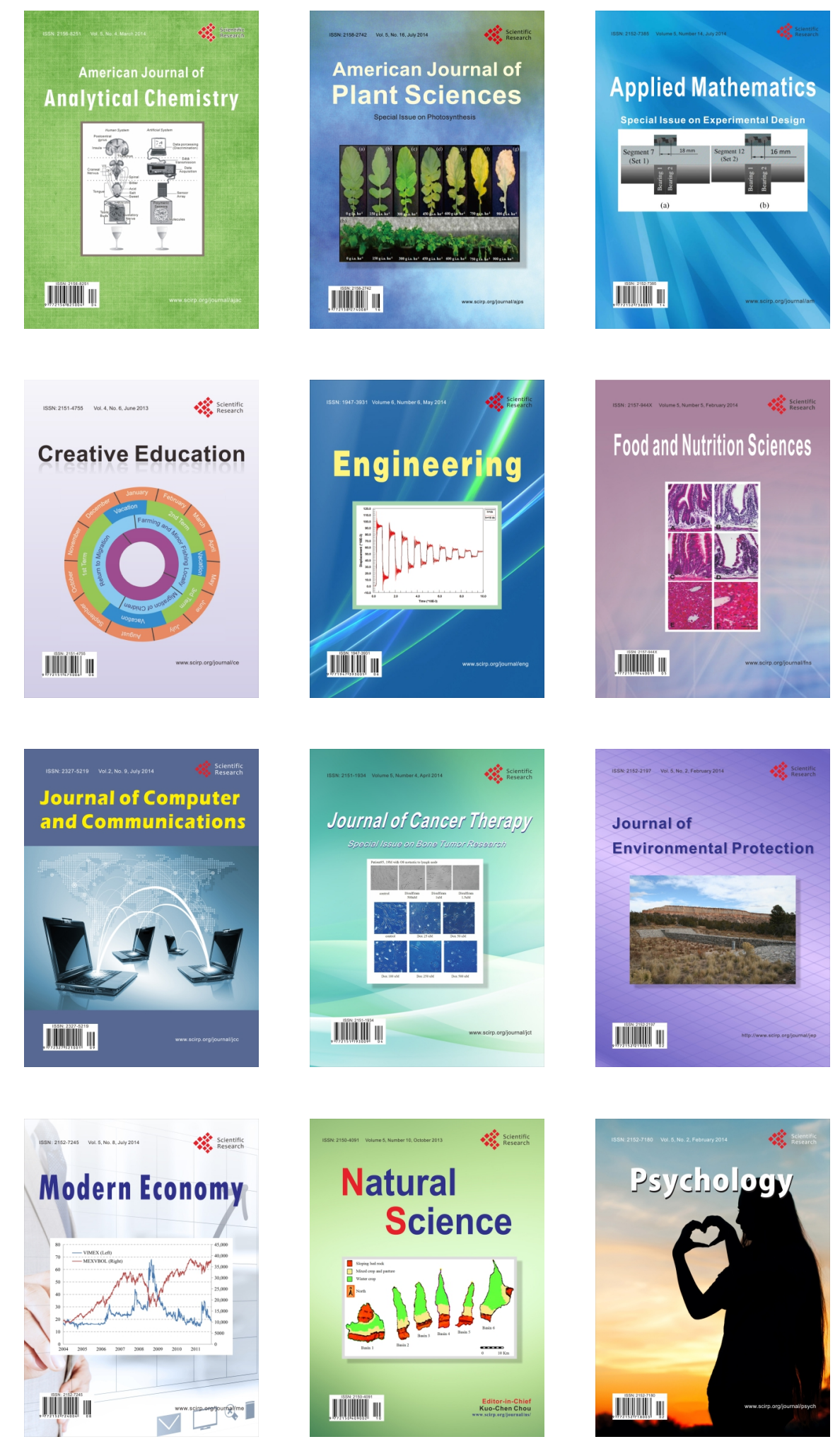